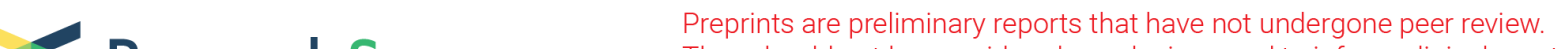

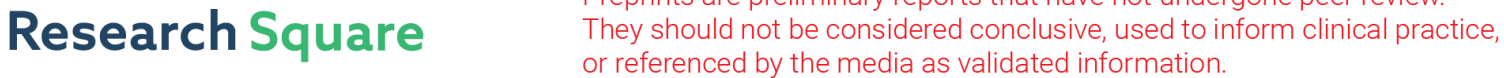

\section{Outcomes of Definitive Chemoradiotherapy for Stage Iva (T4b Vs N4) Esophageal Cancer Based on the Japanese Classification System: A Retrospective Single-center Study}

\section{Yuki Wada ( $\nabla$ ywada@med.akita-u.ac.jp )}

Department of Radiology, Akita University Graduate School of Medicine 1-1-1 Hondo, Akita, Akita 0108543, Japan https://orcid.org/0000-0002-2013-7413

\section{Akira Anbai}

Department of Radilogy, Akita University Graduate School of Medicine Noriko Takagi

Akita University: Akita Daigaku

\section{Satoshi Kumagai}

Department of Radiology, Akita University Graduate School of Medicine

\section{Eriko Okuyama}

Department of Radiology, Akita University Graduate School of Medicine

Hiroshi Nanjo

Akita University: Akita Daigaku

\section{Yusuke Sato}

Esophageal Surgery, Akita University Hospital

\section{Satoru Motoyama}

Esophageal Surgery, Akita University Hospital

\section{Manabu Hashimoto}

Department of Radilogy, Akita University Graduate School of Medicine

\section{Research}

Keywords: esophageal cancer, definitive chemoradiation therapy

Posted Date: October 12th, 2020

DOl: https://doi.org/10.21203/rs.3.rs-89351/v1

License: (c) (i) This work is licensed under a Creative Commons Attribution 4.0 International License. Read Full License 


\section{Abstract}

Background: Based on the Japanese classification of esophageal cancer, Stage IVa involves locally advanced T4b disease and/or lymphatic spread (N4). Stage IVa disease is generally treated using chemoradiotherapy (CRT) for patients in good condition. However, it is unclear whether there are differences in prognoses or progression patterns between T4b non-N4 and non-T4b N4 cases. This study compared the outcomes of CRT for Stage IVa esophageal cancer according to T/N factors.

Methods: We retrospectively identified 68 patients with Stage IVa esophageal cancer who underwent definitive CRT at our center between January 2009 and March 2013. The patients' medical records, diagnostic images, and radiation plans were reviewed, as well as their treatment outcomes, progression patterns, prognostic factors, and toxicities evaluated based on version 5.0 of the National Cancer Institute Common Terminology Criteria for Adverse Events.

Results: The 68 patients (58 men and 10 women) included had a median age of 67 years (range: $37-87$ years). The histological classifications were squamous cell carcinoma (66 patients), adenocarcinoma (one patient), and verrucous carcinoma (one patient). The T/N classifications were T4b non-N4 (29 patients), non-T4b N4 (25 patients), and T4b N4 (14 patients). Local control (complete or partial response) was achieved in 58 patients (85\%). The median overall survival was 13 months (2-year rate: $32.1 \%$ ) and the median progression-free survival was 7 months (2-year rate: $16.4 \%)$. We did not manage to detect significant differences between the $\mathrm{T} / \mathrm{N}$ groups in terms of overall survival, progression-free survival, and progression pattern. Multivariate analyses revealed that independent prognostic factors were nadir hemoglobin and nadir albumin during the CRT period, as well as performance status at CRT initiation. Grade 3 or worse toxicities were observed in 55 patients (81\%), and five patients died because of treatment-related adverse events.

Conclusion: At our center, there were no significant differences in prognoses or progression patterns among patients with T4b non-N4, non-T4b N4, and T4b N4 esophageal cancer. Thus, it seems impractical to modify CRT regimens based on $\mathrm{T} / \mathrm{N}$ factors, and delivering sufficient doses of both radiotherapy and chemotherapy is important for adequately treating Stage IVa esophageal cancer regardless of $\mathrm{T} / \mathrm{N}$ factors.

\section{Background}

Esophageal cancer in Japan has a high mortality rate [1] and was reported in 2016-2017 as the 13th most common cancer [2]. Treatments for esophageal cancer include endoscopic dissection, surgical resection, chemotherapy, and/or external beam radiotherapy, with specific combinations selected according to clinical stage and patient status. Especially in cases of advanced-stage disease, the treatment strategy should be carefully determined by a multidisciplinary team consisting of gastrointestinal physician, esophageal surgeon, medical oncologist, diagnostic radiologist, and radiation oncologist. Definitive chemoradiotherapy (CRT) (50-60 Gy of radiation therapy and concurrent 
chemotherapy mainly with a combination of platina and fluorouracil) is generally provided with curative intent for locally advanced esophageal cancer when the patient's condition is favorable [3].

In Japan, clinical staging of esophageal cancer can be determined based either on the Japanese Classification of Esophageal Cancer (edited by the Japanese Esophageal Society) [4] or the tumor, node, metastasis (TNM) classification of malignant tumors (edited by the Union For International Cancer Control [UICC]) [5]. While both systems assign the clinical stage based on the primary tumor (T factor), regional lymph node metastasis ( $\mathrm{N}$ factor), and distant metastasis ( $\mathrm{M}$ factor), there are several differences between them that are described in additional file 1. In both systems, clinical Stage IVa consists of locally advanced (T4) disease and/or widely spread lymph node metastasis (N4 in the Japanese system and N3 in the UICC system). The standard treatment for Stage IVa disease involves CRT rather than surgical resection, although it is unclear whether there are differences in the failure patterns or survival rates according to the specific T/N factors. Definitive CRT with combination of full dose radiation therapy and full course of chemotherapy can sometimes induce treatment-related toxicities that cause delay or termination in ongoing CRT; thus, it would be favorable to reduce these toxicities by modifying fields or dose of radiation therapy or courses of chemotherapy. To consider this modification, it is important to clarify the recurrence pattern after CRT. Therefore, in this retrospective study we aimed to evaluate the outcomes of CRT for Stage IVa esophageal cancer (based on the Japanese classification) and identify differences according to $\mathrm{T} / \mathrm{N}$ factors that might permit modification of the radiotherapy and/or chemotherapy strategies.

\section{Methods}

\section{Patients}

The protocol of this retrospective study was approved by the institutional review board of our institution (no. 2138, approved on February 21, 2019). Patient consent was not required due to the use of anonymized data. We identified 85 consecutive patients with clinical Stage IVa esophageal cancer who were treated using radiotherapy, with or without other treatment modalities, between January 2009 and March 2013. Clinical staging was performed according to the Japanese Classification of Esophageal Cancer, 11th edition [4]. All patients' stages and treatment strategies were determined by an institutional esophageal cancer board that consisted of esophageal surgeons, gastrointestinal physicians, medical oncologists, diagnostic radiologists, and radiation oncologists.

Among the patients identified, we excluded a total of 17 patients: four who received palliative radiotherapy limited to the primary esophageal lesions, five who did not receive chemotherapy because of their performance status or preference, and eight who became eligible for surgical resection after tumor reduction in response to the definitive CRT (approximate dose of $40 \mathrm{~Gy}$ ). Therefore, this study included 68 patients who intended to receive definitive CRT with at least $50 \mathrm{~Gy}$ of radiation therapy and at least one course of systemic chemotherapy. Their medical records were reviewed to collect data regarding laboratory findings, diagnostic images, radiotherapy planning, sex, age, pathological findings (including 
REG1 expression if available, which may predict the response to CRT) [6], progression-free survival, overall survival, best treatment response, $\mathrm{T} / \mathrm{N}$ factors, and adverse events.

\section{Radiotherapy planning}

All radiotherapy plans were based on three-dimensional conformal radiotherapy. The target volumes were contoured using simulation computed tomography (CT) images, along with pretreatment diagnostic images (obtained using CT and 18F-fluoro-2-deoxy-D-glucose positron emission tomography [18FDGPET]), gastrointestinal endoscopy findings, and clinical examinations, in accordance with the Japanese Society for Radiation Oncology guidelines [7]. The irradiated fields were determined using a combination of the target volume for the primary esophageal lesion and the target volume for the nodal area. The gross tumor volume for the primary esophageal lesion (GTVprimary) was defined based on its length, which was evaluated using radiography, CT, 18FDG-PET, or occasionally endoscopically placed clips. The clinical target volume for the primary lesion (CTVprimary) was defined as the GTVprimary plus an approximate craniocaudal margin of $3 \mathrm{~cm}$ for T1-4 cases (plus the periesophageal fat if clinically T4). The gross tumor volume of the clinically metastatic regional lymph nodes (GTVlymph) was defined based on the nodes' volumes. The CTVlymph was generally equal to the GTVlymph without expansion. However, if extracapsular expansion of the lymph node was suspected, the CTVlymph was defined as the GTVlymph plus a 5-mm margin in all directions.

Although there is controversy regarding elective nodal irradiation [8-11], we generally included the elective nodal area with prophylactic intent. The elective nodal area varied slightly according to the primary lesion's location, and the CTVlympharea was generally determined according to the Japanese Society for Radiation Oncology guidelines [7]. For example, the cervical and abdominal regional lymph nodes are considered within the dissection area for surgical treatment. The planning target volume (PTV) considered PTV1 for the initial irradiation field and PTV2 for boost irradiation: PTV1 = (CTVprimary + CTVlymph + CTVlympharea $)+5-10 \mathrm{~mm}$ in all directions, PTV2 $=($ CTVprimary + CTVlymph $)+5-10 \mathrm{~mm}$ in all directions.

The dose reference point was defined at the iso-center. The radiation dose was 60-61.2 Gy in 30-34 fractions over 6-7 weeks and was administered using high-energy 6-MV or 10-MV photons. Anteriorposterior opposing fields irradiation was initiated for PTV1 (approximately $40 \mathrm{~Gy}$ ), which was followed by oblique portal irradiation fields for PTV2 (approximately $20 \mathrm{~Gy}$ ) to spare the spinal cord.

\section{Chemotherapy}

Three chemotherapy regimens are generally used as part of CRT at our center: high-dose cisplatin (CDDP) plus 5-fluorouracil (5-FU), low-dose CDDP plus 5-FU, and nedaplatin (CDGP) plus 5-FU. These regimens were selected according to the patient's age, performance status, liver/renal function, and other factors. The high-dose CDDP and 5-FU regimen involved an intravenous infusion of CDDP $\left(80 \mathrm{mg} / \mathrm{m}^{2}\right)$ on day 1 plus a continuous intravenous infusion of $5-\mathrm{FU}\left(800 \mathrm{mg} / \mathrm{m}^{2}\right)$ on days $1-5(12)$. The low-dose CDDP and 5 -FU regimen involved an intravenous infusion of $\operatorname{CDDP}\left(40 \mathrm{mg} / \mathrm{m}^{2}\right)$ on days 1 and 8 , as well as 
continuous intravenous infusions of $5-\mathrm{FU}\left(400 \mathrm{mg} / \mathrm{m}^{2}\right)$ on days $1-5$ and $8-12$ [12]. The CDGP and 5-FU regimen involved an intravenous infusion of $\operatorname{CDGP}\left(90 \mathrm{mg} / \mathrm{m}^{2}\right)$ on day 1 plus a continuous intravenous infusion of 5-FU $\left(800 \mathrm{mg} / \mathrm{m}^{2}\right)$ on days 1-5 [13]. The first cycle of chemotherapy was started simultaneously with the radiotherapy, with a plan to administer two chemotherapy cycles during the radiotherapy. However, if Grade 3 or worse hematological toxicities were observed, the second chemotherapy cycle was delayed until the toxicity resolved to Grade 2 or better. Furthermore, if necessary, the drug doses were reduced by $20-30 \%$ according to age, performance status, liver/renal function, and toxicity severity. Continuous adjuvant chemotherapy was performed after the concurrent CRT for patients who experienced tumor response and were able to tolerate additional chemotherapy.

\section{Outcomes}

Treatment responses were evaluated using contrast-enhanced CT and gastrointestinal endoscopy based on version 1.1 of the Response Evaluation Criteria in Solid Tumors [14]. Any adverse events potentially related to CRT were identified using the patient's medical records and re-classified based on version 5.0 of the National Cancer Institute Common Terminology Criteria for Adverse Events [15]. Intervals for progression-free survival (PFS) and overall survival (OS) were the duration until the day that progression or metastasis was firstly identified and the day that patient died calculated from the first day of CRT, respectively.

\section{Statistical analysis}

The Kaplan-Meier method and log-rank test were used to compare the PFS and OS curves according to $\mathrm{T} 4 \mathrm{bN} 0-3, \mathrm{~T} 1-\mathrm{T} 4 \mathrm{aN} 4$, and $\mathrm{T} 4 \mathrm{bN} 4$ status. Relevant prognostic factors were identified using univariate analyses, and significant factors were included in the multivariate Cox proportional hazard model. Based on their reported or probable relationships with survival, the multivariate analysis considered age, nadir hemoglobin, nadir albumin, Eastern Cooperative Oncology Group performance status, nutritional status, and $\mathrm{T} / \mathrm{N}$ factors as explanatory variables. The $\mathrm{T} 4 \mathrm{bNO}-3, \mathrm{~T} 1-\mathrm{T} 4 \mathrm{aN} 4$, and $\mathrm{T} 4 \mathrm{bN} 4$ groups were compared using the Pearson $\mathrm{X}^{2}$ contingency test with Yates correction for categorical variables and the KruskalWallis test for continuous variables. A univariate Cox regression model was used to analyze the recurrence patterns of each $\mathrm{T} / \mathrm{N}$ group to account for the time to progression. Differences were considered statistically significant at $p$-values of $<0.05$; all analyses were performed using BellCurve for Excel (version 3.20; Tokyo, Japan).

\section{Results}

\section{Patient characteristics}

The characteristics of the 68 patients (58 men and 10 women) included in this study are shown in Table 1. The median age at the start of CRT was 67 years (range: 37-87 years). The most common histological type was squamous cell carcinoma (66 patients, 97\%), with one patient having adenocarcinoma (1.5\%) and another patient having verrucous carcinoma (1.5\%). The T/N factor groups 
were T4bN0-3 (29 patients, 43\%), T1-4aN4 (25 patients, 37\%), and T4bN4 (14 patients, 20\%). The most common chemotherapy regimen used was low-dose CDDP/5-FU (51 patients, 75\%), followed by highdose CDDP/5-FU (13 patients, 3\%), 5-FU monotherapy (one patient with low renal function), and CDDP plus docetaxel (one patient). The median follow-up period was 12 months (range: 1-115 months). 
Table 1

Patient characteristics

\begin{tabular}{|c|c|c|c|c|c|}
\hline & $\begin{array}{l}\text { All patients } \\
n=68\end{array}$ & $\begin{array}{l}\text { T4bNO-3 } \\
\mathrm{n}=29\end{array}$ & $\begin{array}{l}\mathrm{T} 1-4 \mathrm{aN} 4 \\
\mathrm{n}=25\end{array}$ & $\begin{array}{l}\text { T4bN4 } \\
n=14\end{array}$ & p-value \\
\hline Age (years) & & & & & 0.4801 \\
\hline Median & 67 & 65 & 67 & 67.5 & \\
\hline Range & $37-87$ & $37-80$ & $44-87$ & $54-86$ & \\
\hline Sex & & & & & 0.2581 \\
\hline Male & 58 & 24 & 24 & 10 & \\
\hline Female & 10 & 5 & 1 & 4 & \\
\hline Histology & & & & & 0.2581 \\
\hline Squamous cell carcinoma & 66 & 28 & 24 & 14 & \\
\hline Adenocarcinoma & 1 & 0 & 1 & 0 & \\
\hline Verrucous & 1 & 1 & 0 & 0 & \\
\hline \multicolumn{6}{|l|}{ Clinical stage } \\
\hline $\mathrm{T} 4 \mathrm{bN} 0-3$ & 29 & 29 & 0 & 0 & \\
\hline T1-4aN4 & 25 & 0 & 25 & 0 & \\
\hline T4bN4 & 14 & 0 & 0 & 14 & \\
\hline Performance status (ECOG) & & & & & 0.7888 \\
\hline $0-1$ & 57 & 23 & 21 & 13 & \\
\hline $2-4$ & 11 & 6 & 4 & 1 & \\
\hline Length of primary lesion & & & & & 0.3486 \\
\hline$\geq 5 \mathrm{~cm}$ & 49 & 24 & 17 & 8 & \\
\hline$<5 \mathrm{~cm}$ & 19 & 5 & 8 & 6 & \\
\hline Eating & & & & & $0.0030 *$ \\
\hline Possible & 13 & 2 & 11 & 0 & \\
\hline Partially possible & 42 & 23 & 11 & 8 & \\
\hline Impossible & 13 & 4 & 3 & 6 & \\
\hline
\end{tabular}

ECOG: Eastern Cooperative Oncology Group, LD-CDDP: low dose cisplatin, 5-FP: 5-fluorouracil, HDCDDP: high dose cisplatin, DTX: docetaxel 


\begin{tabular}{|c|c|c|c|c|c|}
\hline & $\begin{array}{l}\text { All patients } \\
n=68\end{array}$ & $\begin{array}{l}\text { T4bNO-3 } \\
\mathrm{n}=29\end{array}$ & $\begin{array}{l}\mathrm{T} 1-4 \mathrm{aN} 4 \\
\mathrm{n}=25\end{array}$ & $\begin{array}{l}\text { T4bN4 } \\
n=14\end{array}$ & p-value \\
\hline Chemotherapy regimen & & & & & 0.9598 \\
\hline LD-CDDP/5-FP & 51 & 21 & 20 & 10 & \\
\hline HD-CDDP/5-FU & 13 & 7 & 2 & 4 & \\
\hline CDGP/5-FU & 2 & 0 & 2 & 0 & \\
\hline 5-FU & 1 & 0 & 1 & 0 & \\
\hline CDDP/DTX & 1 & 1 & 0 & 0 & \\
\hline Reg1 expression $(n=33)$ & & & & & 0.9887 \\
\hline Positive & 23 & 9 & 10 & 4 & \\
\hline Negative & 10 & 5 & 4 & 1 & \\
\hline
\end{tabular}

Two patients developed residual esophageal cancer after completing CRT and subsequently underwent salvage esophagectomy. Nineteen patients received further treatment for recurrent lesions, which included chemotherapy (14 patients), salvage CRT (two patients with lymph node recurrence outside the irradiated field), endoscopic submucosal dissection (two patients with local recurrence), and salvage surgery (one patient with locoregional lymph node recurrence).

\section{Treatment outcomes}

The best treatment responses were complete response (CR; 11 patients, 16\%), partial response (PR; 47 patients, $69 \%$ ), and stable disease (four patients, $6 \%$ ). Local control (CR + PR) was achieved in 58 patients (85\%), although progressive disease (PD) was observed in six patients (9\%) at first evaluation after starting CRT. Figure 1 shows the PFS and OS curves. The median OS was 13 months, with OS rates of $32.1 \%$ at 2 years and $13.8 \%$ at 5 years. The median PFS was 7 months and the 2 -year PFS rate was $16.4 \%$. A comparison of the T4bN0-3, T1-4aN4, and T4bN4 groups failed to detect significant differences in OS $(p=0.83)$ or PFS $(p=0.91)$.

\section{Progression patterns after CRT}

The treatment failure patterns are summarized in Table 2. No significant differences were observed according to the $\mathrm{T} / \mathrm{N}$ factors. No progression during the observation period was identified in eight patients $(31 \%)$ in the T4bN0-3 group, five patients (22\%) in the T1-4aN4 group, and two patients (14\%) in the T4bN4 group. Progression or recurrence in the T4bN0-3 group occurred inside the irradiated area with/without out-of-field recurrence (eight patients, $28 \%$ ), outside the irradiated area with/without in-field 
recurrence (11 patients, $38 \%$ ), and both inside and outside the irradiated area (one patient, $3.4 \%$ ). In the T1-4aN4 group, progression or recurrence occurred inside the irradiated area with/without out-of-field recurrence (eight patients, $32 \%$ ), outside the irradiated area with/without in-field recurrence (15 patients, $60 \%$ ), and in both areas (four patients, $16 \%$ ). In the T4bN4 group, progression or recurrence occurred inside the irradiated area with/without out-of-field recurrence (six patients, $43 \%$ ) and outside the irradiated area with/without in-field recurrence (six patients, $43 \%$ ).

Table 2

Univariable Cox regression analyses of progression patterns

\begin{tabular}{|c|c|c|c|c|c|c|}
\hline & \multirow[t]{2}{*}{$\begin{array}{l}\text { No } \\
\text { recurrence }\end{array}$} & \multicolumn{2}{|c|}{$\begin{array}{l}\text { In-field recurrence } \\
\text { with/without out-of-field } \\
\text { recurrence }\end{array}$} & \multicolumn{2}{|c|}{$\begin{array}{l}\text { Out-of-field recurrence } \\
\text { with/without in-field } \\
\text { recurrence }\end{array}$} & \multirow[t]{2}{*}{$\begin{array}{l}\text { In- and Out-of- } \\
\text { field } \\
\text { recurrence }\end{array}$} \\
\hline & & Esophagus & Lymph node & $\begin{array}{l}\text { Lymph } \\
\text { node }\end{array}$ & $\begin{array}{l}\text { Distant } \\
\text { organ }\end{array}$ & \\
\hline $\begin{array}{l}\mathrm{T} 4 \mathrm{bNO}- \\
3\end{array}$ & $11(38 \%)$ & $8(28 \%)$ & & 11 (38\%) & & 1 (3.4\%) \\
\hline$n=29$ & & $6(21 \%)$ & $3(10 \%)$ & $4(14 \%)$ & $8(28 \%)$ & \\
\hline T1- & $6(24 \%)$ & 8 (32\%) & & 15 (60\%) & & $4(16 \%)$ \\
\hline $\mathrm{n}=25$ & & $5(20 \%)$ & $6(24 \%)$ & 7 (28\%) & $9(36 \%)$ & \\
\hline T4bN4 & $2(14 \%)$ & $6(43 \%)$ & & $6(43 \%)$ & & $0(0 \%)$ \\
\hline $\mathrm{n}=14$ & & $4(29 \%)$ & $2(14 \%)$ & $1(7.1 \%)$ & 5 (36\%) & \\
\hline $\mathrm{HR}$ & & 1.14 & 1.19 & 0.93 & 1.09 & \\
\hline $95 \% \mathrm{Cl}$ & & $0.60-2.19$ & $0.56-2.53$ & $0.44-1.97$ & $0.64-1.86$ & \\
\hline$p$-value & & 0.691 & 0.656 & 0.848 & 0.757 & \\
\hline
\end{tabular}

\section{Prognostic factors}

Table 3 shows the results of the univariate analyses of OS. Only nadir albumin concentration during CRT was a significant prognostic factor for OS $(p=0.043)$, and no significant differences were observed according to the $T / N$ factors $(p=0.8$ and $p=0.9)$. Table 4 shows the results of the multivariate analyses, which revealed that OS was predicted by the nadir hemoglobin concentration $(p=0.0313)$, nadir albumin concentration $(p=0.043)$, and performance status at CRT initiation $(p=0.0223)$, while the T/N factors did not have prognostic value in the multivariate analyses $(p=0.53$ and 0.31$)$. 
Table 3

Univariant analyses of factors that predicted overall survival

\begin{tabular}{|c|c|c|c|c|}
\hline & no. & Median survival time (months) & $95 \% \mathrm{Cl}$ & p-value \\
\hline \multicolumn{4}{|l|}{ Age (years) } & 0.5170 \\
\hline$>70$ & 21 & 12 & $4.59-19.4$ & \\
\hline$\leq 70$ & 47 & 12 & $8.31-15.7$ & \\
\hline \multicolumn{4}{|c|}{ Initial hemoglobin (g/dL) } & 0.1950 \\
\hline$>10$ & 59 & 13 & $7.42-18.6$ & \\
\hline$\leq 10$ & 9 & 11 & $2.23-19.8$ & \\
\hline \multicolumn{4}{|c|}{ Nadir hemoglobin (g/dL) } & 0.3974 \\
\hline$>10$ & 12 & 17 & $12.0-22.0$ & \\
\hline$\leq 10$ & 56 & 11 & $7.88-14.1$ & \\
\hline \multicolumn{4}{|c|}{ Initial albumin (g/dL) } & 0.7371 \\
\hline$>3.5$ & 41 & 13.0 & $6.82-19.2$ & \\
\hline$\leq 3.5$ & 27 & 12.0 & $5.25-18.7$ & \\
\hline \multicolumn{4}{|c|}{ Nadir albumin $(\mathrm{g} / \mathrm{dL})$} & 0.2727 \\
\hline$>3.5$ & 5 & 26.0 & $8.82-43.2$ & \\
\hline$\leq 3.5$ & 63 & 12.0 & $8.91-15.1$ & \\
\hline \multicolumn{4}{|l|}{ ECOG PS } & $0.0045^{\star}$ \\
\hline $0-1$ & 57 & 14 & $7.7-20.3$ & \\
\hline$\geq 2$ & 11 & 8 & $3.3-12.7$ & \\
\hline \multicolumn{4}{|l|}{$T$ factors } & 0.7061 \\
\hline T4b/any N & 43 & 12 & $10.4-13.6$ & \\
\hline T1-4a/any $\mathrm{N}$ & 25 & 13 & $7.45-18.5$ & \\
\hline \multicolumn{4}{|l|}{$\mathrm{N}$ factors } & 0.9024 \\
\hline N4/any $\mathrm{T}$ & 39 & 14 & $7.93-20.1$ & \\
\hline N0-3/any $T$ & 29 & 10 & $6.5-13.5$ & \\
\hline \multicolumn{4}{|c|}{ Length of primary lesion } & 0.3528 \\
\hline
\end{tabular}

ECOG PS: Eastern Cooperative Oncology Group performance status, Cl: confidence interval 


\begin{tabular}{|lcllll|}
\hline & no. & Median survival time (months) & $95 \% \mathrm{Cl}$ & p-value \\
\hline$>5 \mathrm{~cm}$ & 49 & 10 & $9.97-24.0$ & \\
\hline$\leq 5 \mathrm{~cm}$ & 19 & 17 & $6.59-13.4$ & \\
\hline REG1 expression $(\mathbf{n}=\mathbf{3 4})$ & & & 0.3495 \\
\hline Positive & 23 & 16 & $6.68-25.3$ & \\
\hline Negative & 10 & 11 & $9.48-12.5$ & \\
Eating & & & & 0.9584 \\
\hline Possible & 13 & 16 & $9.98-22.0$ & \\
\hline Partially possible & 42 & 10 & $3.71-16.3$ & \\
\hline Impossible & 13 & 12 & $8.56-15.4$ & \\
\hline ECOG PS: Eastern Cooperative Oncology Group performance status, Cl: confidence interval \\
\hline
\end{tabular}

Table 4

Multivariate analyses of factors that predicted overall survival

\begin{tabular}{|llll|}
\hline & Hazard ratio & $95 \%$ Cl & p-value \\
\hline Age (> 70 vs. $\leq 70$ years) & 0.83 & $0.45-1.55$ & 0.56 \\
\hline Nadir hemoglobin (>10 vs. $\leq 10 \mathrm{~g} / \mathrm{dL})$ & 1.04 & $0.42-2.55$ & 0.94 \\
\hline Nadir albumin (> 3.5 vs. $\leq 3.5 \mathrm{~g} / \mathrm{dL})$ & 1.71 & $0.52-5.62$ & 0.98 \\
\hline ECOG PS (0-1 vs. $\geq 2)$ & 1.68 & $1.14-2.48$ & $0.0093^{\star}$ \\
\hline T factors (T4b vs. $\mathrm{T} 1-4 \mathrm{a})$ & 1.07 & $0.41-2.80$ & 0.90 \\
\hline N factors (N vs. N0-3) & 1.14 & $0.50-2.64$ & 0.75 \\
\hline Length of primary lesion (>5 vs. $\leq 5 \mathrm{~cm})$ & 1.74 & $0.87-3.47$ & 0.12 \\
\hline Eating (possible vs. impossible) & 1.04 & $0.63-1.73$ & 0.87 \\
\hline Cl: confidence interval, ECOG PS: Eastern Cooperative Oncology & Group performance status \\
\hline
\end{tabular}

\section{Toxicities}

Table 5 shows the toxicities of grade 3-5 that occurred in 55 patients (81\%). Late grade 5 adverse events were observed after CRT in five patients ( $7 \%$ ), with the most common being radiation pneumonitis (three patients at 4-15 months after completing CRT). One patient died because of uncontrollable pleural effusion at 58 months after completing CRT, and another patient died because of a fatal esophageal hemorrhage at 3 months after completing CRT. The most common grade 3 or more severe toxicities were hematological (51 patients, 75\%), involving decreased white blood cell count (36 patients, 54\%), anemia 
(22 patients, 32\%), and decreased platelet count (11 patients, 16\%). Grade 3 esophagitis was only observed in four patients. The definition of grade 3 esophagitis is "severely altered eating/swallowing; tube feeding, total parenteral nutrition, or hospitalization indicated" [16], although most patients would already fulfill these criteria based on their locally advanced Stage IVa esophageal cancer; this suggests that the rate of radiation esophagitis might have been underestimated.

Table 5

Toxicities related to chemoradiation therapy $(n=68)$

\begin{tabular}{|llll|}
\hline Toxicity & Grade 3 & Grade 4 & Grade 5 \\
\hline Decreased white blood cell count & $32(47 \%)$ & $5(7 \%)$ & 0 \\
\hline Anemia & $20(29 \%)$ & $2(3 \%)$ & 0 \\
\hline Decreased platelet count & $7(10 \%)$ & $4(6 \%)$ & 0 \\
\hline Increased alanine or aspartate aminotransferase & $2(3 \%)$ & 0 & 0 \\
\hline Hyponatremia & $12(18 \%)$ & $1(1 \%)$ & 0 \\
\hline Hyperkalemia & $4(6 \%)$ & 0 & 0 \\
\hline Hypokalemia & $2(3 \%)$ & $1(1 \%)$ & 0 \\
\hline Esophagitis & $4(6 \%)$ & 0 & 0 \\
\hline Anorexia & $4(6 \%)$ & 0 & 0 \\
\hline Esophageal stenosis & $2(3 \%)$ & 0 & 0 \\
\hline Malaise & $1(1 \%)$ & 0 & 0 \\
\hline Radiation pneumonitis & $5(7 \%)$ & 0 & $3(4 \%)$ \\
\hline Pleural effusion & 0 & 0 & $1(1 \%)$ \\
\hline Febrile neutropenia & $2(3 \%)$ & 0 & 0 \\
\hline Esophageal bleeding & 0 & 0 & $1(1 \%)$ \\
\hline Esophageal fistula & $2(3 \%)$ & 0 & 0 \\
\hline
\end{tabular}

\section{Discussion}

In this study we compared the outcomes of CRT for Stage IVa esophageal cancer according to T/N factors and found a median OS of 13 months, a 2-year OS rate of $32.1 \%$, and a CR rate of $16.2 \%$; local control (complete or partial response) was achieved in $85 \%$ of the patients. However, we did not manage to detect differences among the $\mathrm{T} 4 \mathrm{bNO}-3, \mathrm{~T} 1-4 \mathrm{aN} 4$, and $\mathrm{T} 4 \mathrm{bN} 4$ groups in terms of their progression pattern, PFS, and OS. 
Definitive CRT is standard treatment for Stage IVa esophageal cancer, and there are many global reports on the outcomes from CRT in this setting. Most previous reports have used the UICC TNM classification of malignant tumors and have considered T4 disease with/without M1 (lymph node) to be similar to the group that we evaluated in this study. The previous reports have indicated that the median OS in these cases is 5-14 months [12,17-19], with a 2-year OS rate of $31.5 \%$ [18], and a CR rate of $15 \%$ [18]. One study that used the Japanese classification revealed a median OS of 12.8 months, a 2-year OS rate of $35.1 \%$, and a CR rate of $18.9 \%$ in Stage IVa [20]. Similarly, the present study revealed a median OS of 13 months, a 2-year OS rate of $32.1 \%$, and a CR rate of $16.2 \%$, with local control achieved in 58 patients (85\%). These results are in accordance with those previously reported.

While Stage IVa esophageal cancer includes locally advanced T4b and/or lymph node spread tendency N4; T4bnon-N4, non-T4b N4, and T4b N4 disease, to our knowledge, no previous studies have examined their differences in outcomes or progression patterns. Previous reports showed T4 of UICC is related with poor CR rate of definitive CRT approximately $25-32 \%[12,17,21]$ and increasing numbers of metastatic lymph nodes is related with poor OS rates in operative case studies [22,23]. Our results indicated that the $\mathrm{T} 4 \mathrm{bN} 0-3, \mathrm{~T} 1-4 \mathrm{aN} 4$, and $\mathrm{T} 4 \mathrm{bN} 4$ groups had similar outcomes in terms of progression pattern, PFS, and OS. Previous studies on definitive CRT for esophageal cancer, which included not only Stage IV but also several T/N stages, have also indicated in-field recurrence and out-field recurrence being $40-50 \%$ and $43-50 \%$, respectively $[8,24,25]$. These data suggest that both locoregional and distant recurrences commonly occur after definitive CRT for esophageal cancer. Thus, Stage IVa esophageal cancer with either T4b or N4 requires both sufficient radiotherapy as local treatment and chemotherapy as systemic treatment because progression can occur in and out of the irradiated field, regardless of $\mathrm{T} / \mathrm{N}$ factors.

High toxicity when delivering sufficient radiotherapy and chemotherapy is a common complication. Concurrent CRT can cause significant toxicity $[12,19,26]$, which may necessitate chemotherapy and/or radiotherapy delays or termination. For example, previous reports have indicated that only $50-67 \%$ of patients can complete their scheduled CRT at a planned dose of 50-60 Gy $[27,28]$. The present study found that $81 \%$ of the patients experienced grade 3 or more severe toxicities and particularly $75 \%$ of the patients experienced grade 3 or more severe hematological toxicities, possibly leading to termination or delay in CRT. Previous studies that used nearly the same CRT regimen with elective nodal irradiation (ENI) setting have shown that grade 3 or more severe leukopenia, anemia, and thrombopenia were $73 \%, 30-$ $33 \%$, and $14-36 \%$, respectively $[21,26]$. Therefore, while radiation and chemotherapy doses may need to be maintained to achieve optimal results, it is important to consider strategies that can reduce toxicity and enable patients to complete their planned treatment.

One conceivable strategy for managing toxicity is to modify the radiation dose. However, in a previous study that compared CRT using the same chemotherapy regimen and a substantial radiation dose reduction ( 50 Gy vs. $30 \mathrm{~Gy}$ ), inferior OS at the lower radiation dose was found [29]. The INT 0123 trial that included randomized patients with unresectable esophageal cancer who received CRT using radiation doses of $64.8 \mathrm{~Gy}$ or $50.4 \mathrm{~Gy}$, revealed that the higher dose did not provide superior locoregional control, leading to the broad adoption of $50.4 \mathrm{~Gy}$ as the standard radiation dose [30]. However, the introduction of 
newer radiotherapy techniques, such as image-guided radiation therapy, intensity modulated radiation therapy, and charged particle therapy, have led researchers to re-consider dose escalation in the French Concorde trial [31]. Unsatisfactory local control has been observed in Japan based on results from the JCOG9516 [18] and JCOG0303 trials [19], which has prompted our center to generally use a radiation dose of $60 \mathrm{~Gy}$ [32]. While further studies are needed to better understand the required radiation dose in this setting, it will be probably difficult to achieve satisfactory results with a dose of $<50 \mathrm{~Gy}$.

Another strategy for managing toxicity is to modify the irradiated field. For example, treatment may be limited to the gross lesions while excluding the elective nodal area, which is known as involved field radiation therapy (IFRT). The elective nodal area has historically been targeted during CRT for esophageal cancer, based on the lymph node dissection pattern for definitive surgery in these cases, although it is unclear whether it is truly useful to target the elective nodal area in radiation therapy. Thus, it remains unclear whether ENI or IFRT should be preferred for esophageal cancer, although several retrospective studies have suggested that IFRT may provide advantages in terms of local control [8] and distant metastasis $[8,10]$. Those reports have also indicated that IFRT produced less toxicity than ENI, which suggests that patients may be more likely to complete their planned chemotherapy, thereby improving the treatment of distant metastasis. Moreover, if recurrence occurs in an area that was prophylactically irradiated using a dose of approximately $40 \mathrm{~Gy}$, it would not be feasible to perform definitive radiotherapy at a dose of > 50 Gy at the same area, which may preclude salvage CRT for the recurrent lesion and worsen local control and OS [33]. Neo-adjuvant CRT for esophageal cancer provides a pathological CR rate of only $23-68 \%$ when various chemotherapy regimens were combined with a radiation dose of approximately $40 \mathrm{~Gy}$ [34-39]. Thus, a prophylactic dose of $40 \mathrm{~Gy}$ may be insufficient to achieve local control and might preclude adequate salvage CRT if the patient experiences local lymph node recurrence. Although ENI may reduce regional nodal failure $[24,40]$, these recent studies suggest that prophylactically expanding the irradiation field may not be prudent to reduce toxicities, especially hematological, and complete planned definitive CRT.

The present study has two important limitations. First, there are differences between the Japanese and UICC staging systems, as well as country-specific differences in the histological types and accumulated doses. Second, the findings of this study are limited by the small retrospective single-center design. Thus, it is possible that our findings may not be replicated in other centers or regions. However, this study did not manage to detect differences among the T4bN0-3, T1-4aN4, and T4bN4 groups in terms of their progression pattern, PFS, and OS. Thus, our data suggest that sufficient dose of both radiation and chemotherapy is needed to improve treatment outcome of Stage IVa esophageal cancer regardless the $\mathrm{T} / \mathrm{N}$ factors. However, it remains important to manage reduction in radiation-related toxicity, and it may be prudent to consider modifying the irradiated field (e.g., using IFRT) to improve the outcomes of definitive CRT for locally advanced esophageal cancer.

\section{Conclusions}


Similar to previous reports, the present study revealed that definitive CRT for Stage IVa esophageal cancer was associated with a median OS of 13 months and a 2-year OS rate of $32.1 \%$. However, we failed to detect differences in the progression sites and survival rates between cases that involved T4b or N4 disease. Thus, these factors are likely not useful for modifying the chemoradiotherapy strategy in this setting, and further studies are needed to determine whether outcomes can be improved by modifying the prescribed dose and irradiated field (e.g., only targeting the gross lesions).

\section{List Of Abreviations}

18FDG-PET, 18F-fluoro-2-deoxy-D-glucose positron emission tomography; 5-FU, 5-fluorouracil; CDDP, cisplatin; CDGP, nedaplatin; CR, complete response; CRT, chemoradiotherapy; CT, computed tomography; CTV, primary clinical target volume for the primary lesion; ENI, elective nodal irradiation; GTV, primary gross tumor volume for the primary esophageal lesion; GTVlymph, gross tumor volume of the clinically metastatic regional lymph nodes; IFRT, involved field radiation therapy; OS, overall survival; PD, progressive disease; PFS, progression-free survival; PR, partial response; PTV, planning target volume; TNM, tumor, node, metastasis; UICC, Union for International Cancer Control

\section{Declarations}

Ethics approval and consent to participate: The study's retrospective protocol was approved by the Akita University Hospital institutional review board (no. 2138, approved on February 21, 2019). All methods were performed in accordance with the guidelines and regulations of the ethics board. Patient consent was not required based on the use of anonymized data.

Consent for publication: Not applicable.

Availability of data and materials: All relevant data are included in the manuscript and its accompanying files.

Competing interests: The authors declare that they have no competing interests.

Funding: The study was financially supported by Akita University Support for Young Scientists.

Authors' contributions: Study concept and design (YW, AA, SM, MH); data acquisition (NT, SK, EO, YS, HN); data analysis and interpretation (YW, AA); statistical analysis (YW); and drafting of the manuscript (YW). All authors have read and approved the final version of the manuscript.

Acknowledgements. We thank Editage for English language editing.

\section{References}

1. Cancer Registry and Statistics. Cancer Information Service, National Cancer Center, Japan (Vital Statistics of Japan) https://ganjoho.jp/en/professional/statistics/table_download.html. Accessed 5 
Oct 2020.

2. Cancer Registry and Statistics. Cancer Information Service, National Cancer Center, Japan (Ministry of Health, Labour and Welfare, National Cancer Registry) https://ganjoho.jp/en/professional/statistics/table_download.html. Accessed 5 Oct 2020.

3. Kitagawa Y, Uno T, Oyama T, Kato K, Kato H, Kawakubo H, et al. Esophageal cancer practice guidelines 2017 edited by the Japan Esophageal Society: part 1. Esophagus. 2019;16:1-24.

4. Japan Esophageal Society. Japanese Classification of Esophageal Cancer, 11th Edition: part I. Esophagus. 2017;14:1-36.

5. Brierley JD, Gospodarowicz MK, Wittekind C: Oesophagus (ICD-0-3 C15) Including Oesophagogastric Hunction (C 16.0). In: Brierley JD, Gospodarowicz MK, Wittekind C, editors. TNM Classification of Malignant Tumours, 8th Edition. WILEY: Blackwell; 2017. P. 57-62.

6. Hayashi K, Motoyama S, Koyota S, Koizumi Y, Wang J, Takasawa S, et al. REG I enhances chemoand radiosensitivity in squamous cell esophageal cancer cells. Cancer Sci. 2008;99:2491-5.

7. The Japanese Guideline for Radiation Planning. 2016. https://www.jastro.or.jp/medicalpersonnel/guideline/2016/05digestive_apparatus.pdf. Acessed 25 Feb 2019.

8. Yamashita H, Takenaka R, Omori M, Imae T, Okuma K, Ohtomo K, et al. Involved-field radiotherapy (IFRT) versus elective nodal irradiation (ENI) in combination with concurrent chemotherapy for 239 esophageal cancers: A single institutional retrospective study. Radiat Oncol. 2015;10:171.

9. Cheng YJ, Jing SW, Zhu LL, Wang J, Wang L, Liu Q, et al. Comparison of elective nodal irradiation and involved-field irradiation in esophageal squamous cell carcinoma: a meta-analysis. J Radiat Res. 2018;59:604-15.

10. Wang X, Miao C, Chen Z, Li W, Yuan S, Yu J, et al. Can involved-field irradiation replace elective nodal irradiation in chemoradiotherapy for esophageal cancer? A systematic review and meta-analysis. Onco Targets Ther. 2017;10:2087-95.

11. Li M, Zhang X, Zhao F, Luo Y, Kong L, Yu J. Involved-field radiotherapy for esophageal squamous cell carcinoma: Theory and practice. Radiat Oncol. 2016;11:1-9.

12. Ohtsu A, Boku N, Muro K, Chin K, Muto M, Yoshida S, et al. Definitive chemoradiotherapy for T4 and/or M1 lymph node squamous cell carcinoma of the esophagus. J Clin Oncol. 1999;17:2915-21.

13. Kato K, Muro K, Ando N, Nishimaki T, Ohtsu A, Aogi K, et al. A phase II study of nedaplatin and 5fluorouracil in metastatic squamous cell carcinoma of the esophagus: The Japan Clinical Oncology Group (JCOG) Trial (JCOG 9905-DI). Esophagus. 2014;11:183-8.

14. Eisenhauer EA, Therasse P, Bogaerts J, Schwartz LH, Sargent D, Ford R, et al. New response evaluation criteria in solid tumours: Revised RECIST guideline (version 1.1). Eur J Cancer. 2009;45:228-47.

15. Common Terminology Criteria. for Adverse Events version 5.0. https://ctep.cancer.gov/protocolDevelopment/electronic_applications/ctc.htm\#ctc_50. Acessed 3 Dec 2019. 
16. National Institute of Health. Common Terminology Criteria for Adverse Events (CTCAE). http://ctep.cancer.gov/protocolDevelopment/electronic_applications/docs/ctcaev3.pdf. Accessed 5 Oct 2020.

17. Nishimura Y, Suzuki M, Nakamatsu K, Kanamori S, Yagyu Y, Shigeoka H. Prospective trial of concurrent chemoradiotherapy with protracted infusion of 5-fluorouracil and cisplatin for T4 esophageal cancer with or without fistula. Int J Radiat Oncol Biol Phys. 2002;53:134-9.

18. Ishida K, Ando N, Yamamoto S, Ide H, Shinoda M. Phase II study of cisplatin and 5-fluorouracil with concurrent radiotherapy in advanced squamous cell carcinoma of the esophagus: A Japan esophageal oncology group (JEOG)/Japan clinical oncology group trial (JCOG9516). Jpn J Clin Oncol. 2004;34:615-9.

19. Shinoda M, Ando N, Kato K, Ishikura S, Kato H, Tsubosa Y, et al. Randomized study of low-dose versus standard-dose chemoradiotherapy for unresectable esophageal squamous cell carcinoma (JCOG0303). Cancer Sci. 2015;106:407-12.

20. Anbai A, Koga M, Motoyama S, Jin M, Shibata H, Hashimoto M. Outcomes of patients with stage IVA esophageal cancer (Japanese classification) treated with definitive chemoradiotherapy. Jpn J Radiol. 2013;31:270-6.

21. Kaneko K, Ito H, Konishi K, Kurahashi T, Ito T, Katagiri A, et al. Definitive chemoradiotherapy for patients with malignant stricture due to T3 or T4 squamous cell carcinoma of the oesophagus. $\mathrm{Br} \mathrm{J}$ Cancer. 2003;88:18-24.

22. Nishimaki T, Suzuki T, Suzuki S, Kuwabara S, Hatakeyama K. Outcomes of extended radical esophagectomy for thoracic esophageal cancer. J Am Coll Surg. 1998;186:306-12.

23. Natsugoe S, Yoshinaka H, Shimada M, Sakamoto F, Morinaga T, Nakano S, et al. Number of lymph node metastases determined by presurgical ultrasound and endoscopic ultrasound is related to prognosis in patients with esophageal carcinoma. Ann Surg. 2001;234:613-8.

24. Welsh J, Settle SH, Amini A, Xiao L, Suzuki A, Hayashi Y, et al. Failure patterns in patients with esophageal cancer treated with definitive chemoradiation. Cancer. 2012;118:2632-40.

25. Di Fiore F, Lecleire S, Rigal O, Galais MP, Soussan E, Ben, David I, et al. Predictive factors of survival in patients treated with definitive chemoradiotherapy for squamous cell esophageal carcinoma. World J Gastroenterol. 2006;12:4185-90.

26. Yamashita H, Okuma K, Wakui R, Kobayashi-Shibata S, Ohtomo K, Nakagawa K. Details of recurrence sites after elective nodal irradiation (ENI) using 3D-conformal radiotherapy (3D-CRT) combined with chemotherapy for thoracic esophageal squamous cell carcinoma - A retrospective analysis. Radiother Oncol. 2011;98:255-60.

27. Sauter ER, Coia LR, Keller SM. Preoperative high-dose radiation and chemotherapy in adenocarcinoma of the esophagus and esophagogastric junction. Ann Surg Oncol. 1994;1:5-10.

28. Herskovic A, Martz K, al-Sarraf M, Leichman L, Brindle J, Vaitkevicius V, et al. Combined Chemotherapy and Radiotherapy Compared with Radiotherapy Alone in Patients with Cancer of the Esophagus. N Engl J Med. 1992;326:1593-8. 
29. Herskovic A, Leichman L, Lattin P, Han I, Ahmad K, Gail Leichman C, et al. Chemo/radiation with and without surgery in the thoracic esophagus: The wayne state experience. Int J Radiat Oncol Biol Phys. 1988;15:655-62.

30. Minsky BD, Pajak TF, Ginsberg RJ, Pisansky TM, Martenson J, Komaki R, et al. INT 0123 (Radiation Therapy Oncology Group 94 - 05) Phase III Trial of Combined-Modality Therapy for Esophageal Cancer: High-Dose Versus Standard-Dose Radiation Therapy. J Clin Oncol. 2002;20:1167-74.

31. Crehange G, Bonnetain F, Peiffert D, Le Prise E, Etienne P-L, Rio E, et al. Phase II/III randomized trial of exclusive chemoradiotherapy with or without dose escalation in locally advanced esophageal carcinoma: The CONCORDE study (PRODIGE 26). J Clin Oncol. 2016;34:TPS190-0.

32. Nishimura Y, Jingu K, Itasaka S, Negoro Y, Murakami Y, Karasawa K, et al. Clinical outcomes of radiotherapy for esophageal cancer between 2004 and 2008: the second survey of the Japanese Radiation Oncology Study Group (JROSG). Int J Clin Oncol. 2016;21:88-94.

33. Jingu K, Niibe Y, Yamashita H, Katsui K, Matsumoto T, Nishina T, et al. Re-irradiation for oligorecurrence from esophageal cancer with radiotherapy history: A multi-institutional study. Radiat Oncol. 2017;12:4-9.

34. Van Hagen P, Hulshof MCCM, Van Lanschot JJB, Steyerberg EW, Van Berge Henegouwen MI, Wijnhoven BPL, et al. Preoperative chemoradiotherapy for esophageal or junctional cancer. $\mathrm{N}$ Engl J Med. 2012;366:2074-84.

35. Ruhstaller T, Templeton A, Ribi K, Schuller JC, Borner M, Thierstein S, et al. Intense therapy in patients with locally advanced esophageal cancer beyond hope for surgical cure: A prospective, multicenter phase ii trial of the swiss group for clinical cancer research (SAKK 76/02). Onkologie. 2010;33:2228.

36. Meluch AA, Greco FA, Gray JR, Thomas M, Sutton VM, Davis JL, et al. Preoperative therapy with concurrent paclitaxel/carboplatin/infusional 5-FU and radiation therapy in locoregional esophageal cancer: Final results of a minnie pearl cancer research network phase II trial. Cancer J. 2003;9:25160.

37. Bates BA, Detterbeck FC, Bernard SA, Qaqish BF, Tepper JE. Concurrent radiation therapy and chemotherapy followed by esophagectomy for localized esophageal carcinoma. J Clin Oncol. 1996;14:156-63.

38. Ruhstaller T, Widmer L, Schuller JC, Roth A, Hess V, Mingrone W, et al. Multicenter phase II trial of preoperative induction chemotherapy followed by chemoradiation with docetaxel and cisplatin for locally advanced esophageal carcinoma (SAKK 75/02). Ann Oncol Off J Eur Soc Med Oncol. 2009;20:1522-8.

39. Ajani JA, Walsh G, Komaki R, Morris J, Swisher SG, Putnam JB, et al. Preoperative induction of CPT11 and cisplatin chemotherapy followed by chemoradiotherapy in patients with locoregional carcinoma of the esophagus or gastroesophageal junction. Cancer. 2004;100:2347-54.

40. Onozawa M, Nihei K, Ishikura S, Minashi K, Yano T, Muto M, et al. Elective nodal irradiation (ENI) in definitive chemoradiotherapy (CRT) for squamous cell carcinoma of the thoracic esophagus. 
Figures
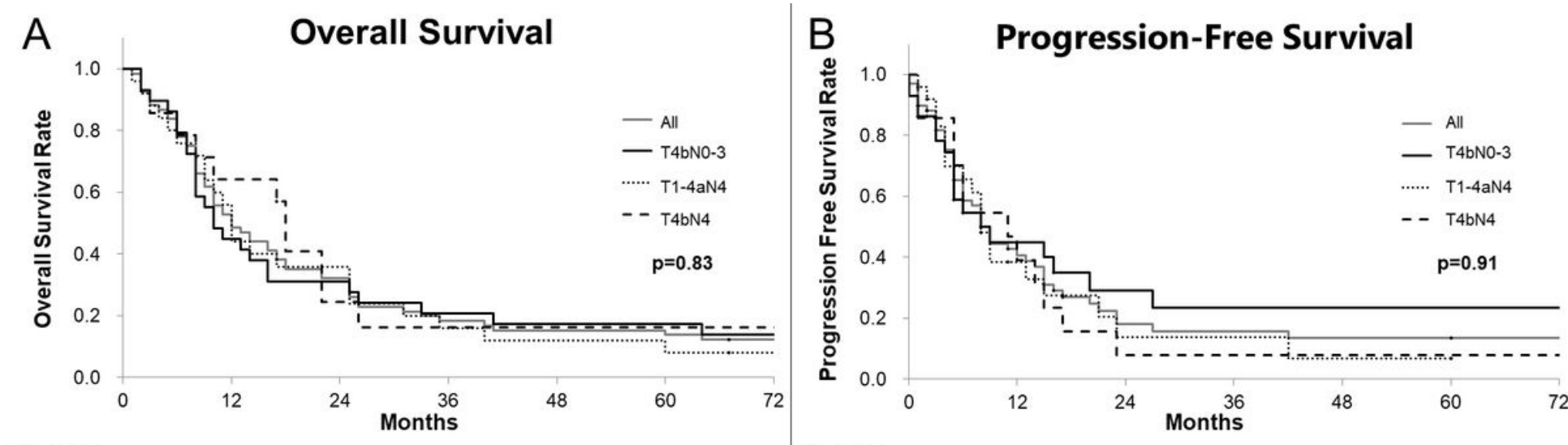

$\begin{array}{rrrrrrrr}\text { No. at risk } & & & & & & & \\ \text { All } & 68 & 36 & 23 & 13 & 11 & 10 & 8 \\ \text { T4bN0-3 } & 29 & 14 & 11 & 7 & 6 & 6 & 5 \\ \text { T1-4aN4 } & 25 & 14 & 10 & 5 & 4 & 3 & 2 \\ \text { T4bN4 } & 14 & 10 & 5 & 3 & 3 & 3 & 3\end{array}$

$\begin{array}{rrrrrrrr}\text { No. at risk } & & & & & & \\ \text { All } & 68 & 22 & 10 & 8 & 7 & 6 & 6 \\ \text { T4bN0-3 } & 29 & 10 & 6 & 5 & 5 & 5 & 5 \\ \text { T1-4aN4 } & 25 & 8 & 3 & 3 & 2 & 1 & 1 \\ \text { T4bN4 } & 14 & 6 & 2 & 1 & 1 & 1 & 1\end{array}$

\section{Figure 1}

Kaplan-Meier curves for overall survival (OS) (A) and progression-free survival (PFS) (B). (A) Among all patients, the median OS was 13 months, with rates of $32.1 \%$ at 2 years and $13.8 \%$ at 5 years. There were no significant differences in OS between the patients with each T/N factor $(p=0.8)$. (B) Among all patients, the median PFS was 8 months and the 2-year PFS rate was $18 \%$. There were no significant differences in PFS between the patients with each T/N factor $(p=0.7)$.

\section{Supplementary Files}

This is a list of supplementary files associated with this preprint. Click to download.

- AdditionalFile1.docx 